\title{
PHYOTOCHEMICAL SCREENING AND ANTI-MICROBIAL SCREENING OF POTENTIAL INVASIVE SPECIES FOUND AT AROUND PAKLIHAWA, NEPAL
}

\author{
Subodh Khanal ${ }^{1 *}$ and Krishna Neupane ${ }^{2}$ \\ ${ }^{1}$ Paklihawa Campus, Institute of Agriculture and Animal Science \\ ${ }^{2}$ Tennessee State University, USA \\ *subodh.agroecology@gmail.com
}

\begin{abstract}
Weed management is one of the great issues in the agroecosystem of this contemporary world. The invasiveness is negatively impacting human and ecosystem as a whole. In this regard, a comparative study was done to investigate the potential phytochemicals and anti-microbial properties present in the problematic invasive species distributed at around Paklihawa Campus, Siddharthanagar, Nepal. Four species viz. Eichornia, Parthenium, Pistia and Ipomoea were selected and the chemical was screened using aqueous methanol as selective menstruum through cold percolation. The fractionated extracts showed the presence of some phytochemicals including alkaloids, saponins, carbohydrates and steroids. Pistia was screening positively for alkaloids, carbohydrates, flavonoids, saponin and steroid; Parthenium for alkaloids, flavonoids and steroids; Eichornia for alkaloids and carbohydrates whereas Ipomoea showed the presence of alkaloids only. The extracts were also screened for antibacterial and antifungal activities. The leaf extracts were used to assess antimicrobial activities against bacteria: Staphylococcus aureus, Escherichia coli, Klebsiella pneumonia and Salmonella typhimurium, and fungi: Aspergillus niger, Candida albicans, Alternaria solani and Fusarium solani using the well diffusion method. The results indicated that the leaf extracts of Parthenium exhibited more zone of inhibition against all bacteria and has potential to be used as anti-bacterial agent. In majority of fungus also, Parthenium was superior to others. The Minimum inhibitory concentration (MIC) values against the tested bacteria ranged from 11 to $19 \mu \mathrm{g} \mathrm{mL}^{-1}$ and for the tested pathogenic fungi, from 10 to $20 \mu \mathrm{g} \mathrm{mL}^{-1}$. This result showed that these invasive species could be promising antibacterial and anti-fungal agents.
\end{abstract}

Key words: Anti-microbial, invasive, phytochemicals, screening, weeds

\section{INTRODUCTION}

A weed is defined as a plant that grows out of a place and is competitive, persistent and pernicious (James et al. 1991). The resistance of weeds to microbes is more when compared to cultivated crops. The resistance nature and their sustenance towards the microbial disease made us have the interest to know the potency behind. Invasive alien species are animals, plants or other organisms that are introduced into places outside their natural range, negatively impacting native biodiversity, ecosystem services or human wellbeing (IUCN, 2017). Hence, the present study is conducted to screen the phytochemicals and antimicrobial potency of weeds that are invasive in nature. The logic behind the selection of species was to see their potential use as botanicals.

Many plants and weeds, in particular, have biologically active chemical components that may be used in the treatment of various 
ailments and plant protection measures as well, but, so far, very few have been identified and used accordingly. The use of plant extracts and phytochemicals, both with known antimicrobial properties, can be of great significance in therapeutic treatments (Srivastava et al. 1996; Dahiya and Purkayastha 2012).

Phytochemicals are bioactive chemicals of plant origin and are regarded as secondary metabolites as the plants use them for protective and attractive purpose. They are naturally synthesized in all parts of the plant body, such as bark, leaves, stem, root, flower, fruits, seeds etc. i.e. any part of the plant body may contain these active compounds (Sushma Raj, 2017). Phyotochemical screening refers to the extraction, screening and identification of the medicinally active substances found in plants using standardized procedure. Some of the bioactive substances that can be identified and derived from plants are flavonoids, alkaloids, carotenoids, tannins, antioxidants and phenolic compounds (Senguttuvan et al. 2014). In the last few years, a number of studies have been conducted in different countries to test the efficiency of various plants. It is due to the secondary metabolites which are equipped with several antimicrobial traits. Such metabolites can be of great use to society. Invasive species are problematic in various ecosystems throughout the world. The management of invasive species is a cumbersome task. In this regard, this study focused to analyze the phytochemical profile of various invasive species and to evaluate its antimicrobial activity against various selected pathogens.

\section{MATERIALS AND METHODS}

Site selection: For the collection of plant samples to be used in phytochemical screening, wetland area adjacent to Dande River and Paklihawa Campus was chosen. The area is wasteland where a lot of invasive species are found among them, four of the most problematic ones were selected. Two species were from terrestrial habitat and two were selected from aquatic habitat. The of the selected site is $27.481^{\circ} \mathrm{N}$ and $83.444^{\circ} \mathrm{E}$.

\section{Collection of plant samples}

The collection of plant samples was done at around Paklihawa Campus. The leaves were picked and washed with water thoroughly to remove all unwanted plant materials and sand, air dried under diffused light exposure $\left(27^{\circ} \mathrm{C}-30^{\circ} \mathrm{C}\right.$ for 14 days), pulverized in a mill and stored in an airtight container for further use.

\section{Preparation of extract}

Ten gram of plant powder was added to $100 \mathrm{ml}$ of methanol in a conical flask and plugged with cotton wool. After 24 hours the supernatant was collected and the solvent was evaporated to make the crude extract and stored at $4^{\circ} \mathrm{C}$ (Harbone, 1973; Tiwari et al. 2011). The extraction was carried out by cold percolation method and was filtered using Whatman's filter paper no.42. The supernatant was evaporated at $45^{\circ} \mathrm{C}$ to make the final volume $1 / 5^{\text {th }}$ of the original volume.

\section{Phytochemical Screening}

For the phytochemical screening of selected invasive weed species, standard qualitative methods previously described by (Sasidharan et al. 2011) was followed. Following tests were performed for detecting major phytoconstituents.

\section{Detection of flavonoids}

Shinoda test: A piece of magnesium ribbon and concentrated hydrochloric acid was added to 2-3 $\mathrm{ml}$ of methanolic extracts. Pink red or red coloration of the solution indicated the presence of flavonoids.

Alkaline reagent test: To the $5 \mathrm{ml}$ of the test solution, $2 \mathrm{ml}$ of $2 \%$ of $\mathrm{NaOH}$ was added. 
Formation of an intense yellow color, which turns to colorless on the addition of a few drops of diluted acids, indicated the presence of flavonoids.

\section{Detection of tannins}

Braemer's test: $10 \%$ of alcoholic ferric chloride was added to $2-3 \mathrm{ml}$ of methanolic extracts (1:1). Dark blue or greenish grey coloration of the solution indicated the presence of tannins.

\section{Detection of terpenoids}

Salkowski test: $2 \mathrm{ml}$ of chloroform and $3 \mathrm{ml}$ of concentrated sulphuric acid were added to $5 \mathrm{ml}$ of methanolic extracts. The reddish brown color of interface indicated the presence of terpenoids.

\section{Detection of saponins}

Foam test: The extracts of $50 \mathrm{mg}$ were first diluted with distilled water and volume was adjusted to $20 \mathrm{ml}$. The suspension was then shaken vigorously in a graduated cylinder for 15 minutes. A $2 \mathrm{~cm}$ layer of foam indicated the presence of saponins.

\section{Detection of phenols}

Ferric chloride test: $50 \mathrm{mg}$ of extracts were dissolved in $5 \mathrm{ml}$ of distilled water. To this, a few drops of neutral $5 \%$ ferric chloride solution was added. A dark green color indicated the presence of the phenol compound.

\section{Detection of alkaloids}

Solvent free extracts $(50 \mathrm{mg})$ was stirred with $3 \mathrm{ml}$ of diluted hydrochloric acid and filtered. The filtrate was tested carefully with various alkaloids reagents. After that following (Mayer's test) was performed: To a few $\mathrm{ml}$ of filtrate, 1 or 2 drops of Mayer's reagent was added by the side of the test tube. Formation of white creamy precipitates indicated the presence of alkaloids.

\section{Detection of glycosides}

$0.5 \mathrm{~g}$ of solvent extracts were dissolved in $2 \mathrm{ml}$ of glacial acetic acid containing one drop of ferric chloride solution. It was then under laid with $1 \mathrm{ml}$ of concentrated sulphuric acid. A brown ring at the interface indicated the presence of glycosides.

\section{Detection of fixed oils and fats}

A drop of concentrated extracts was pressed in between two filter papers and kept undisturbed. Oils stain on the paper indicated the presence of oils and fats.

\section{Detection of carbohydrates}

Fehling's test: Equal volume of Fehling A and Fehling $\mathrm{B}$ reagents are mixed together and $2 \mathrm{ml}$ of it was added to crude extracts. It was boiled gently. A brick red precipitate appeared at the bottom of the test tube indicated the presence of reducing sugars.

\section{Detection of steroids}

Cured extracts were mixed with $2 \mathrm{ml}$ of chloroform and concentrated sulphuric acid was added sidewise. A red color produced in the lower chloroform layer indicated the presence of steroids.

\section{Anti-microbial test}

The antibacterial activity was determined by well diffusion method (Bauer et al. 1966). The medium was sterilized by autoclaving and was allowed to cool down at the room temperature. Filter discs $(5.5 / \mathrm{mm})$ were made and impregnated with the solution. The discs were dried at $37^{\circ} \mathrm{C}$ for $1 \mathrm{~h}$. Muller Hinton's agar plates were used for in vitro antimicrobial testing. Bacterial strains were sub cultured from frozen stocks or from freshly obtained plates.

Muller Hinton agar medium was seeded with $100 \mu 1$ of inoculum $(1 \times 108 \mathrm{CFU} / \mathrm{ml})$. The impregnated discs containing the test sample $(100 \mu \mathrm{g} / \mathrm{ml})$ were placed on the agar medium seeded with tested microorganisms. The plates were then incubated at $37^{\circ} \mathrm{C}$ for $24 \mathrm{hr}$ to allow maximum growth of the microorganisms (Bauer 
et al. 1966). The antibacterial activity of the test samples was determined by measuring the diameter of zone of inhibition expressed in millimeter. The assay was repeated twice and the mean of the three experiments was recorded. Controls were maintained where pure solvents were used instead of plant extracts.

Disc diffusion method given by Bauer was adopted for the determination of the antifungal activity of the extract residues. From the stock cultures of various test organisms, the inoculum was prepared by sub culturing each of the organisms on potato dextrose agar at $37^{\circ} \mathrm{C}$. Seeding of potato dextrose agar plates was done using the $24 \mathrm{hr}$ culture with a cotton swab under aseptic conditions. The discs loaded with extract residues were aseptically placed on top of the seeded medium and gently pressed to ensure contact. The plates were then incubated at $37^{\circ} \mathrm{C}$. After overnight incubation, the plates were observed for zones of inhibition. Controls were maintained similar as for anti-bacterial test.

\section{Minimum inhibitory concentration (MIC) measurements}

A current definition of the minimum inhibitory concentration (MIC) is the lowest concentration which resulted in maintenance or reduction of inoculums viability (Carson et al. 1995). The MIC of the crude methanol extracts was determined by using serial dilution technique (Reiner, 1982). The serial tube dilution technique was used to determine the MIC value of methanol extracts of these plants against bacteria and fungi. The extract $(0.512 \mathrm{mg})$ was dissolved in $2 \mathrm{~mL}$ distilled water to obtain the stock solution. After preparation of suspensions of test organisms $\left(10^{7}\right.$ organisms per $\left.\mathrm{mL}\right), 1$ drop of suspension $(0.02 \mathrm{~mL})$ was added to each broth dilution. After $24 \mathrm{~h}$ incubation at $37^{\circ} \mathrm{C}$, the tubes were then examined for growth. The MIC of the extract was taken as the lowest concentration that showed no growth. Growth was observed in those tubes where the concentration of the extract was below the inhibitory level and the broth medium was observed to be turbid. Experiments were done in triplicate and repeated twice.

\section{RESULT AND DISCUSSION}

The preliminary phytochemical analysis of Pistia, Parthenium, Eichornia and Ipomoea, when dissolved in methanol, is presented in table 1. Based on the result, we suggest that Pistia possesses alkaloids, carbohydrates, saponins and steroids. Pistia showed positive test for alkaloids, carbohydrates, flavonoids, saponin and steroid. Parthenium positively responded to alkaloid, flavonoid and steroid. Alkaloids and carbohydrates were screened in Eichornia. Whereas, Ipomoea was responsive to alkaloid test only. Phytochemical screening of various plants is reported by (Siddiqui et al. 2009; Chitradivu et al. 2009; Juna Beegum et al. 2014). 
Table 1: Result of phyotochemical screening of various invasive species found at around Paklihawa, 2016.

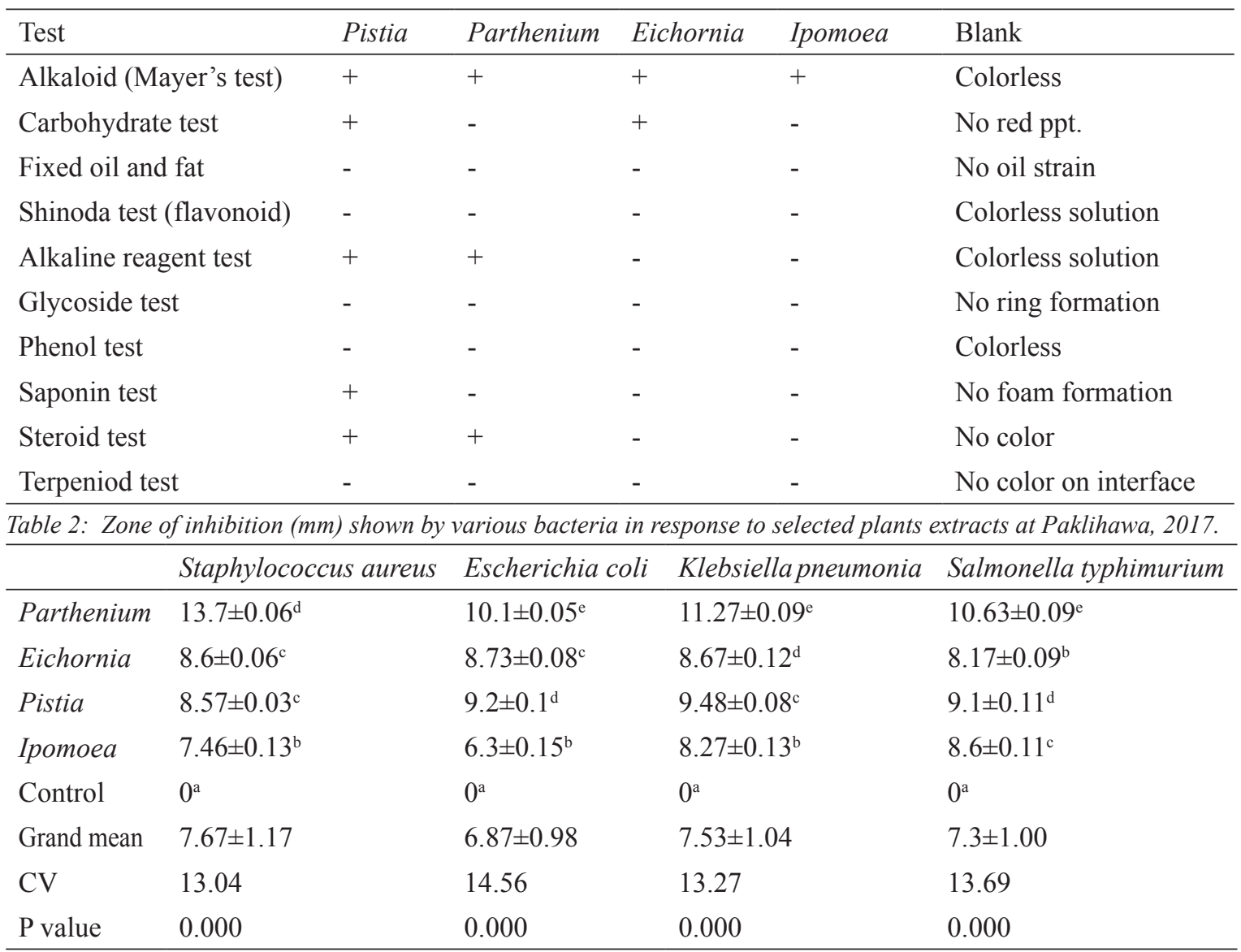

Zone of inhibition was found significantly different between the treatments. Maxmimum activity was seen in Parthenium for all the studied bacteria. Eichornia and Pistia were at par to each other for Staphylococcus aureus. Ipomoea was least responsive for Staphylococcus aureus, Escherichia coli, Klebsiella pneumonia whereas Eichornia was least performer for Salmonella typhimurium.

The results also indicated that the extracts from the plants studied showed inhibition of growth against tested microorganisms with to various degrees. It revealed that the methanolic extract of various invasive species has broad spectrum antimicrobial activities as visualized by zone of inhibition formed. The result for antibacterial and antifungal activity is as shown in table 2 and table 3. A clear zone of growth inhibition was found around the wall because of diffusion of compounds. The diameter of the inhibition zone differed according to the relative susceptibility of the test microorganisms to a particular antimicrobial agent. 
Phyotochemical Screening and Anti-Microbial Screening ...

Table 3: Zone of inhibition ( $\mathrm{mm}$ ) shown by various fungi in response to selected plants extracts at Paklihawa, 2017

\begin{tabular}{lllll}
\hline & Aspergillus niger & Candida albicans & Alternaria solani & Fusarium spp \\
\hline Parthenium & $10.73 \pm 0.37^{\mathrm{b}}$ & $16.56 \pm 0.29 \mathrm{c}$ & $11.66 \pm 0.66^{\mathrm{b}}$ & $9.03 \pm 0.03^{\mathrm{c}}$ \\
Eichornia & $10.56 \pm 0.52^{\mathrm{b}}$ & $14.9 \pm 0.49 \mathrm{~b}$ & $11.36 \pm 0.31^{\mathrm{b}}$ & $7.66 \pm 0.04^{\mathrm{b}}$ \\
Pistia & $10.3 \pm 0.50^{\mathrm{b}}$ & $14.23 \pm 0.78 \mathrm{~b}$ & $11.60 \pm 0.30^{\mathrm{b}}$ & $8.67 \pm 0.33^{\mathrm{bc}}$ \\
Ipomoea & $10.50 \pm 0.43^{\mathrm{b}}$ & $14.63 \pm 0.31 \mathrm{~b}$ & $12.53 \pm 0.53^{\mathrm{b}}$ & $8.02 \pm 0.05^{\mathrm{bc}}$ \\
Control & $0.00^{\mathrm{a}}$ & $0.00 \mathrm{a}$ & $0.00^{\mathrm{a}}$ & $0.00^{\mathrm{a}}$ \\
Grand mean & $8.42 \pm 1.14$ & $12.06 \pm 1.62$ & $9.42 \pm 1.27$ & $6.68 \pm 0.9$ \\
CV & 23.75 & 24.86 & 21.2 & 22.47 \\
P value & 0.000 & 0.000 & 0.000 & 0.000
\end{tabular}

No significant difference was noted in the zone of inhibition for Aspergillus niger and Alternaria solani, however, for Candida albicans, Parthenium showed maximum activity. In case of Fusarium spp, maximum activity was seen for Parthenium, however, it was as par with Pistia and Ipomoea.

\section{Minimum inhibitory concentration (MIC) measurement:}

The impact of aqueous methanol extract against the selected tested bacteria and fungi was assessed as Minimum Inhibitory Concentration (MIC) values of the extracts. The MIC values against the tested bacteria ranged from 11 to $19 \mu \mathrm{g} \mathrm{mL}^{-1}$ and for the tested pathogenic fungi, from 10 to 20 $\mu \mathrm{g} \mathrm{mL}^{-1}$ (Table 4). The MIC assay indicated that Parthenium, Eichornia, Pistia and Ipomoea have antibacterial and antifungal activities against all tested bacteria and fungi at a lower concentration.

Table 4: Minimum inhibitory concentration (MIC) of various invasive plant leaves extract on pathogenic bacteria determined by modified agar well diffusion method

\begin{tabular}{lllll}
\hline Extract & Staphylococcus aureus & Escherichia coli & Klebsiella pneumoniae & Salmonella typhimurium \\
\hline Parthenium & $11.06 \pm 0.03^{\mathrm{a}}$ & $15.1 \pm 0.06^{\mathrm{b}}$ & $17.1 \pm 0.06^{\mathrm{b}}$ & $16.05 \pm 0.03^{\mathrm{a}}$ \\
Eichornia & $16.14 \pm 0.08^{\mathrm{c}}$ & $18.1 \pm 0.06^{\mathrm{d}}$ & $18.09 \pm 0.06^{\mathrm{c}}$ & $18.06 \pm 0.03^{\mathrm{b}}$ \\
Pistia & $16.13 \pm 0.06^{\mathrm{c}}$ & $16.1 \pm 0.05^{\mathrm{c}}$ & $17.05 \pm 0.03^{\mathrm{b}}$ & $16.05 \pm 0.04^{\mathrm{a}}$ \\
Ipomoea & $14.16 \pm 0.08^{\mathrm{b}}$ & $14.2 \pm 0.05^{\mathrm{a}}$ & $16.09 \pm 0.06^{\mathrm{a}}$ & $19.09 \pm 0.06^{\mathrm{c}}$ \\
Grand mean & $11.5 \pm 1.61$ & $12.68 \pm 1.73$ & $13.66 \pm 1.83$ & $13.85 \pm 1.87$ \\
$\mathrm{CV}$ & 17.38 & 14.07 & 15.77 & 14.63 \\
P value & 0.000 & 0.000 & 0.000 & 0.000 \\
\hline
\end{tabular}

The minimum inhibitory concentration (MIC) required for Staphylococcus aureus was found to be least in Parthenium $(11.06 \pm 0.03)$ which was significantly lower than other extracts. For Escherichia coli, MIC was found to be least and statistically significant in Iomoea extracts (14.16 \pm 0.08$)$. For Klebsiella pneumoniae, MIC was lower in Pistia(17.05 \pm 0.03$)$ but as par with Parthenium(17.1 \pm 0.06$)$. In the case of Salmonella typhimurium, MIC was as par with both Parthenium (16.05 \pm 0.03$)$ and Pistia (16.05 \pm 0.04$)$. 
Table 5: Minimum inhibitory concentration (MIC) of various invasive plant leaves extract on pathogenic fungi determined by modified agar well diffusion method

\begin{tabular}{lllll}
\hline Extract & Aspergillus niger & Candida albicans & Alternaria solani & Fusarium spp \\
\hline Parthenium & $17.04 \pm 0.03^{\mathrm{b}}$ & $12.05 \pm 0.03^{\mathrm{a}}$ & $14.03 \pm 0.04^{\mathrm{b}}$ & $17.02 \pm 0.02^{\mathrm{a}}$ \\
Eichornia & $14.04 \pm 0.03^{\mathrm{a}}$ & $15.06 \pm 0.03^{\mathrm{b}}$ & $14.03 \pm 0.03^{\mathrm{b}}$ & $17.03 \pm 0.03^{\mathrm{a}}$ \\
Pistia & $17.05 \pm 0.04^{\mathrm{b}}$ & $17.06 \pm 0.03^{\mathrm{c}}$ & $19.02 \pm 0.03^{\mathrm{c}}$ & $16.99 \pm 0.01^{\mathrm{a}}$ \\
Ipomoea & $17.08 \pm 0.06^{\mathrm{b}}$ & $19.02 \pm 0.03^{\mathrm{d}}$ & $10.22 \pm 0.22^{\mathrm{a}}$ & $20.01 \pm 0.01^{\mathrm{b}}$ \\
Grand mean & $13.04 \pm 1.77$ & $12.63 \pm 1.79$ & $11.46 \pm 1.7$ & $14.21 \pm 1.92$ \\
CV & 14.43 & 15.33 & 15.83 & 17.44 \\
P value & 0.000 & 0.000 & 0.000 & 0.000 \\
\hline
\end{tabular}

The MIC for Aspergillus niger was least and significantly different in Eichornia extracts (14.04. \pm 0.03$)$, Candida albigans in Parthenium extracts (12.05 \pm 0.03$)$ and Alternaria solani in Ipomoea extracts $(10.22 \pm 0.22)$. However, MIC results for Fusarium spp were as par with Parthenium, Eichornia and Pistia. These results of antimicrobial activity of different extracts of E. crassipes were similar to the results found by others authors (Jayanthi et al. 2011; Thamaraiselvi et al. 2012).

\section{CONCLUSIONS}

The usage of the selected plants for the medicinal purpose has been reported by several researchers. However, these are invasive in nature and are supposed to be toxic in nature so, further investigations are to be done before establishing them as standard medicinal plants or specific plant protection measures. The present study shows potential phytochemicals present in Parthenium, Eichornia, Pistia and Ipomoea. Moreover, these plants showed to have a good antibacterial and anti-fungal activity in the aerial parts of selected plants. The finding of this study also paves the way for further research to identify the specific bioactive compounds that are responsible for its claimed antimicrobial activity. Based on this study, it is concluded that under different circumstances the invasive plants might be used for modern therapeutics to prepare potential drugs and plant protection measures. Such study will explore other pharmacological activity of unexplored weeds inhabited in and around western Nepal. Detailed study, is however needed in this regard.

\section{REFERENCES}

Bauer, A. W., W.M. M. Kirby, J. C. Sherries, and M. Tuck. (1966). Antibiotic Susceptibility Testing By Standardized Disc Diffusion Method. American Journal of Clinical Pathology, 45: 493-496.

Carson, C.F., K.A. Hammer, and T.V. Riley. (1995). Broth microdilution method for determining the susceptibility of Escherichia coli and Staphylococcus aureus to the essential oil of Melaleuca alternifolia (tea tree oil), Microbios 82: 181-185.

Chitradivu, C., S. Manian, and K. Kalaichelvi. (2009). Qualitative analysis of selected medicinal plants, Tamilnadu, India. Middle Scientific Research, 4 (3): 144-146.

Dahiya, P., and S. Purkayastha. (2012). Phytochemical Screening and Antimicrobial Activity of Some Medicinal Plants Against Multi-drug Resistant Bacteria from Clinical Isolates. Indian Journal of Pharamceutical Sciences 74 (5): 443-450.

Harbone, J. B. (1973). Phytochemical Methods. London: Chapman and Hill. 
IUCN. (2017). Invasive alien species and climate change.

James, L., J. Evans, M. Ralphs, and R. Child. (1991). Noxious Range Weeds. Boulder, CO: Westview Press.

Jayanthi, P., P. Lalitha, and K.S. Shubashini. (2011). Phytochemical investigation of the solvents extracts and fractionates of Eichhornia crassipes. Journal of Pharmacy Reesearch, 4: 1405-1406.

Juna Beegum, G. R., S. Suhara Beevy, and V. S. Sugunan. (2014). Nutritive and anti-nutritive properties of Boerhaavia diffusa L. Journal of Pharmacognosy and Phytochemistry, 147-151.

Reiner, R. (1982).Antibiotics-An Introduction. Basle, Switzerland: F. Hoffman La Roche and Co.

Sasidharan, S., Y. Chen, D. Saravaran, K.M. Sundaram, and L.Y. Latha. (2011). Extraction, Isolation and Cahracterization of Bioactive Compounds From Plant's Extracts. Afr. J. Tradit. Complement. Altern. Med., 8: 1-10.

Senguttuvan, J., S. Paulsamy, and K. Karthika. (2014.) Phytochemical Analysis and Evaluation of Leaf and Root Parts of the medicinal Herb, Hypochaeris radiata L. for Invitro Oxidant Activities." Asian Pacific Journal of Tropical Biomedicine 4 (Suppl 1): $\mathrm{S} 359-\mathrm{S} 367$.

Siddiqui, S., A. Verma, A.A. Rather, F. Jabeen, and M.K. Meghvansi. (2009.) Preliminary phytochemical analysis of some important medicinal and aromatic plants. Advance Biological Research 3 (5-6): 188-195.
Srivastava, J., J. Lambert, and M. Vietmeyer. (1996). Medicinal Plants: An Expanding Role in Development. Washington DC, USA: The World Bank.

Sushma Raj, R.V. (2017). Preliminary phytochemical screening of Lantana camara, L., a major invasive species of Kerala, using different solvents. Annals of Plant Science 6(11): 1794-1798.

Thamaraiselvi, P., P. Lalitha, and P. Jayanthi. (2012). Preliminary studies on phytochemicals and antimicrobial activity of solvent extracts of Eichhornia crassipes (Mart.) Solms. Asian Journal of Plant Science and Research, 2 (2): 115-122.

Tiwari, P., B. Kumar, M. Kaur, G. Kaur, and H. Kaur. 2011. Phytochemical screening and Extraction: A Review. Internationale Pharmaceutica Sciencia 1 (1).

Received 11 April 2018

Revised accepted 28 July 2018 